\title{
The Diversified Teaching Mode Reform of Hydraulic and Pneumatic Transmission
}

\author{
Liping Xu \\ School of mechanical and electrical engineering \\ Henan University of Science and Technology \\ Luoyang, China \\ email:xlpzz@163.com
}

\author{
Haoyi Ma \\ School of mechanical and electrical engineering \\ Henan University of Science and Technology \\ Luoyang, China \\ email:253279482@qq.com
}

\author{
Jian Li \\ School of mechanical and electrical engineering \\ Henan University of Science and Technology \\ Luoyang, China \\ email:ly-sword@126.com
}

\begin{abstract}
With the development of national industrial level, the demand for innovative talents is higher and higher Hydraulic and Pneumatic Transmission is a course with strong practicality and comprehensiveness. Traditional teaching mode only pays attention to the teaching of theoretical knowledge and neglect the training of engineering practice ability. The complete training system of this course should include: the function of hydraulic components, the cognition of functional symbols, the functional analysis of hydraulic system, the layout of hydraulic system and the design of the hydraulic pump station, the control of hydraulic system in PLC and the production practice of this course. However, traditional teaching mode only gives attention to the first two parts of the content, which is not conducive to the component of students' knowledge system. On basis of the current situation, in this article, we improve the traditional single teaching mode and propose a diversified teaching mode. The new teaching mode is designed in order to establish a complete knowledge system and improve students' ability to solve engineering practice.
\end{abstract}

Keywords - theory teaching, traditional teaching mode, practice teaching, diversified, knowledge system;

\section{INTRODUCTION}

Hydraulic and Pneumatic Transmission is one of the fastest growing technologies in machinery field. Especially in recent years, along with the development of mechanical and electrical integration technology, which promote this technology to enter a new stage of development. Hydraulic and pneumatic technology is widely used in engineering because of its remarkable technical characteristics, such as construction machinery, metallurgical machinery, ships, aerospace, weapons and equipment, agriculture and forestry machinery, simulation platform, packaging machinery, test equipment and automatic production line and so on. Therefore, we should pay enough attention to the teaching of this course, Moreover, we should not only emphasize the theoretical teaching, but also develop the ability to solve practical problems.[1]

\section{INVESTIGATION ON THE LEARNING SITUATION OF HYDRAULIC AND PNEUMATIC TRANSMISSION}

In January 2016, a survey was carried out based on 109 students with good grades of the course in eight universities. The examination content mainly includes three items: the functional analysis of hydraulic system, the layout of hydraulic system and the design of the hydraulic pump station, the control of hydraulic system in PLC, the diagram of hydraulic system are shown in Fig.1.

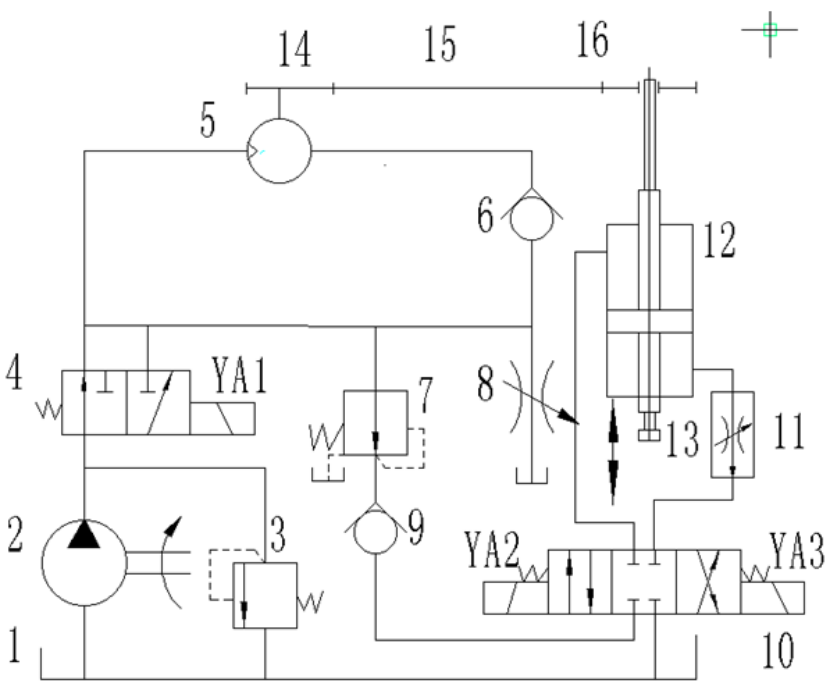

Fig. 1. The diagram of hydraulic system

According to the statistics, there are nearly $83 \%$ of school students can only deal with the functional analysis of hydraulic system and they have never heard of the layout of hydraulic system, the design of the hydraulic pump station and the control of hydraulic system in PLC. There are only about $7 \%$ of students can solve all the problems by themselves and about $10 \%$ of students can't solve each of the problems. 
From what has been mentioned above, we can come to the conclusion that most of students who can deal with the functional analysis of hydraulic system well have poor capacity to the design of the hydraulic pump station and the control of hydraulic system in PLC. The reason for this kind of situation is that school has misunderstanding in the teaching method. They often pay more attention to the theory teaching, while the attention to the cultivation of students' practical ability is not enough.[2]

For the Course Orientation of Hydraulic and Pneumatic Transmission, Hydraulic and Pneumatic Transmission is the basis introduction of hydraulic technology, which can lay the foundation for the future hydraulic industry. It plays a significant role for students' future study of hydraulic. However, by the investigation, we also find the teaching system of some colleges and universities often put too much energy into some theoretical teaching, such as, the function of hydraulic components and the cognition of functional symbols, the functional analysis of hydraulic system while the layout of hydraulic system and the design of the hydraulic pump station, the control of hydraulic system in PLC are often as a self-study content or simply presented in class and it often does not be put forward higher requirements. What's more, most colleges and universities do not set the hydraulic practice link at all. Such a training model is not conducive to the development of students.[3]

Taking into account the limited teaching hours, we should reduce the time of teaching on the function of hydraulic components and the cognition of functional symbols, the functional analysis of hydraulic system by improvement of classroom teaching and save time to the teaching of the design of the hydraulic pump station and the control of hydraulic system in PLC. This method doesn't mean not attach importance to the basic teaching, it is to improve the utilization rate of the classroom and increase the students' self-study time after class. The component diagram of complete knowledge system is shown in Fig.2.[4]

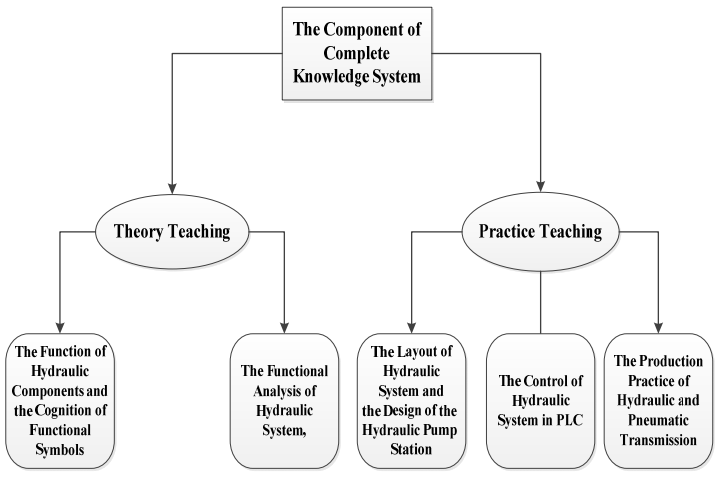

Fig. 2. The component diagram of complete knowledge system

\section{THE REFORM AND PRACTICE OF THE THEORY TEACHING OF HYDRAULIC AND PNEUMATIC TRANSMISSION}

A. The Function of Hydraulic Components and the Cognition of Functional Symbols

Hydraulic components are the basis of hydraulic technology. The reasonable selection of hydraulic components is an important link to improve the working performance of hydraulic system. In the process of class teaching, we should pay close attention to the links between the components, such as, overflow valve, pressure relief valve and sequence valve. We should grasp the same points and different points of them in process of teaching. In this way, we can not only enable students to understand the hydraulic components more deeply, but also can reduce the time of teaching on hydraulic components and save more time for other aspect.

\section{B. The Functional Analysis of Hydraulic System}

The functional analysis of hydraulic system is one of the most important sections in hydraulic technology because by the process of it can not only strengthen the knowledge of hydraulic components, but also deepen the understanding of the function of the hydraulic system.

In my opinions, the learning of hydraulic system should be divided into three steps: learn to analyze hydraulic system, learn to improve the original hydraulic system and learn to design a new hydraulic system. In the course of teaching, we should actively cultivate students' interest. Furthermore, we should explore its function by instance to draw inferences about other cases from one instance.[5]

\section{THE REFORM AND PRACTICE OF THE PRACTICE TEACHING OF HYDRAULIC AND PNEUMATIC TRANSMISSION}

\section{A. The Layout of Hydraulic System and the Design of the Hydraulic Pump Station}

The layout of hydraulic system mainly includes the design of the hydraulic pump station and integrated block. The main purpose is to let students learn how to layout the whole hydraulic system. We should take into account the rationality of the layout, which both to ensure the aesthetic of the layout and consider how to reduce the pressure loss. A reasonable layout mode can improve system efficiency and save production cost. The layout of hydraulic system has played a great role in promoting the training of students' engineering practice ability. In this way, students should realize that the reasonable principle design is only the first step to the complete engineering project and there are also lots of problems to solve. As a education worker, we should try to change students the way of thinking from theoretical analysis to practical engineering.

\section{B. The Control of Hydraulic System in PLC}

With the development of hydraulic technology, most hydraulic systems have realized automatic control in PLC. The control of hydraulic system in PLC as an important part of hydraulic technology, we should pay enough attention to it. The combination of PLC technology and hydraulic technology not only can achieve simple logic control, but also can achieve precise position control, force control and speed control. The distributed control system in PLC is shown in Fig.3. By the leaning of the control of hydraulic system, students can both consolidate the knowledge of PLC control and deepen the understanding of hydraulic knowledge. This method can train students' practical application ability. 


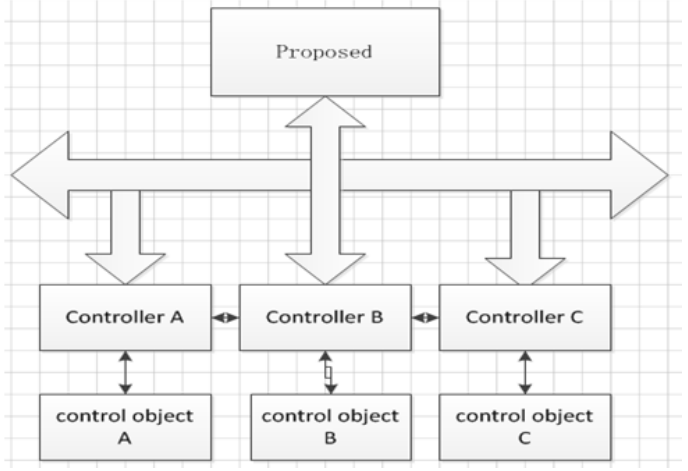

Fig. 3. Distributed Control System in PLC

\section{The Production Practice of Hydraulic and Pneumatic Transmission}

Hydraulic and Pneumatic technology is a subject with strong practicality and application, the simple classroom teaching has been difficult to meet the needs of students learning. Field teaching should also be included in the training program. Theory teaching and field teaching are complementary. On one hand, field teaching is on the basis of classroom teaching and it is a kind of sublimation of classroom teaching. On the other hand, field teaching can strengthen the theoretical teaching. Taking inclined axial plunger for example, based on the observation of the physical object, students can grasp the structural characteristics of pump and the assembly relation between the plunger and the cylinder, the sliding shoe and the slanting plate more easily than the traditional classroom teaching.[6,7] The actual hydraulic station on the spot is shown in Fig.4. The observation of actual field can make the boring classroom teaching become more vivid. What's more, it can also exercise the students' practical ability in the process of visiting.

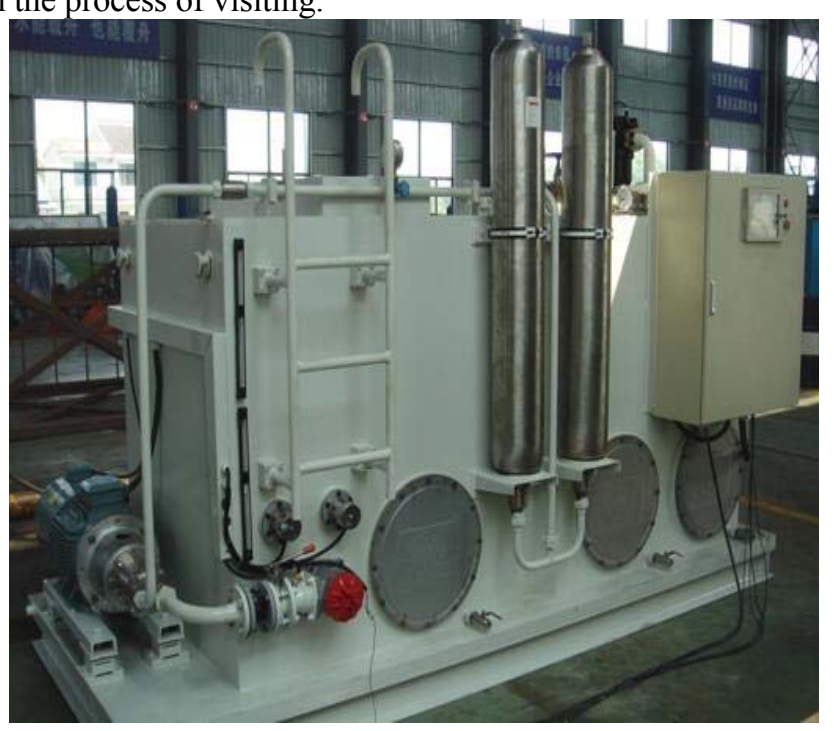

Fig. 4. Hydraulic station layout on the spot

\section{THE DiVERSIFIED TEACHING Mode REFORM QUESTIONNAIRE INVESTIGATION}

Recently, our school held a teaching reform forum, the meeting invited teachers, students and business representatives for more than 40 people to participate in and the reform of the project to investigate. According to statistics, about $76 \%$ of the students, $70 \%$ of the teachers and $81 \%$ corporate leadership support of the diversified teaching mode reform of Hydraulic and Pneumatic Transmission, part of students, teachers and enterprise representatives also published their views on the question. Up to now, some colleges and universities have adopted the new reform program.

\section{CONCLUSION}

New teaching mode changes the traditional teaching mode of single theory teaching. It combines theory teaching and practice teaching. At the same time to improve the practical ability, students' theoretical knowledge has also been consolidated.[8] New teaching mode is more conducive to the overall development of students. Compared to the traditional teaching mode, it has the following advantages.

- New teaching mode make the training system more complete, which contributes to the establishment of a complete knowledge system for students.

- New teaching mode with the combination of theory and practice can make it easier for students to understand.

- New teaching mode makes the boring teaching more vivid, which improves students' learning interest.

- New teaching mode on the basis of the theory of pay more attention to the cultivation of students practical application ability

\section{ACKNOWLEDGMENT}

The authors gratefully acknowledge the superior course of HAUST for financial support of this research work.

\section{REFERENCES}

[1] M.Fuling $\mathrm{Xu}$, Yaoming Chen. Hydraulic and Pneumatic Transmission. BeiJing: Machinery Industry Press, May 2007.

[2] M.Zhijian Huang. Hydraulic control system and PLC application. BeiJing: China Electric Power Press, December 2011.

[3] J.Xiwei Peng. A Research and Practice of Teaching Innovation in Course Hydraulic and Pneumatic Drive, vol.34 No.2 Mar.2011, pp.142-144.

[4] M.Zhuangyun Li.Hydraulic components and systems BeiJing: Hydraulic components and systems BeiJing: Machinery Industry Press, June 2011.

[5] M.Chunxing Wang. The hydraulic control system. Beijing: Beijing industry press, June 2015.

[6] J.Chundong Yao, Dianrong Gao, Dong Jun. Exploration and Practice on the teaching reform of hydraulic and pneumatic transmission, vol.29 No.2 May.2006,pp156-160

[7] J.Shuang Meng, Qiyun Yang,Zugen Yan, Haifu Li Ming Pang.Application of engineering examples in the teaching of hydraulic and pneumatic transmission

[8] J.Nianjin Ding. Teaching system reconstruction: a necessity. Journal of hunan normal university education sciences, vol 1, 2015, pp.51-57. 